\section{BC successfully restricts use of trans fat in food service establishments}

Eisenberg and colleagues' analysis article in CMAJ describes a number of government-level interventions in public health, including imposing regulatory limits on trans fat. ${ }^{1}$ Although the authors mention some national efforts to regulate trans fat, the British Columbia Ministry of Health wishes to draw attention to one initiative not menioned in their article - the BC Trans Fat Initiative, which was successfully implemented in our province.

Launched in 2009, this legislative intervention has successfully restricted industrially produced trans fat in all British Columbia food service establishments. The initiative includes the first health impediments regulation under the new Public Health Act to recognize the harmful effects of trans fat on the health of British Columbians. In partnership with the Heart and Stroke Foundation of $\mathrm{BC} \&$ Yukon and in collaboration with the food industry, a number of resources and supports were developed to assist industry in making the required changes. These include a website (www.restricttransfat.ca), 8-1-1 HealthLink BC phone line and translated informational materials. Environmental health officers have been enforcing the regulation and have completed over 30000 inspections. Food service establishments have achieved close to $90 \%$ compliance.

The Ministry of Health is committed to helping British Columbians live healthy and active lifestyles and is pleased to take this opportunity to share our success in restricting trans fat in British Columbia.

Lisa Forster-Coull

Provincial Nutritionist

Perry Kendall MD

Provincial Health Officer

BC Ministry of Health, Victoria BC

\section{Reference}

1. Eisenberg MJ, Atallah R, Grandi SM, et al. Legislative approaches to tackling the obesity epidemic. CMAJ 2011;183:1496-1500.

CMAJ 2011. DOI:10.1503/cmaj.111-2081

\section{Let us reconsider}

The article in the Sept. 6 issue of CMAJ about sex-selective abortion in China (and elsewhere) was read with interest. ${ }^{1}$ Western societies have long promoted abortion-on-demand and have insisted that the discussion of reproductive health be kept between doctor and patient. We screen for "defects" such as Down syndrome and spina bifida, and taxpayer funds cover the termination of unwanted pregnancies.

The abortion-on-demand philosophy has extended to the use of medications such as Plan B, which is available in pharmacies without a prescription. A woman in Canada can find out the gender of her unborn child and decide at less than 20 weeks to have an abortion. Western culture has gone to great lengths to make abortion-on-demand part of medical "rights" around the world.

This sounds like we are reaping what we have sown, and that this is not a Chinese problem, but a worldwide problem. This writer would encourage a reconsideration of the policy of abortion-on-demand.

\section{John Loge MD}

Private practice, Bonnyville, Alta.

\section{Reference}

1. Hesketh T, Lu L, Wei Xing Z. The consequences of son preference and sex-selective abortion in China and other Asian countries. CMAJ 2011;183:1374-7.

CMAJ 2011. DOI:10.1503/cmaj.111-2096

\section{Letters to the editor}

In submitting a letter, you automatically consent to have it appear online and/or in print. All letters accepted for print will be edited by CMAJ for space and style. Most references and multiple authors' names, full affiliations and competing interests will appear online only. (The full version of any letter accepted for print will be posted at cmaj.ca.) 